\title{
Meteorological table, for April 1810
}

\section{Mr. Carey}

To cite this article: Mr. Carey (1810) Meteorological table, for April 1810, Philosophical Magazine Series 1, 35:144, 320-320, DOI: 10.1080/14786441008563088

To link to this article: http://dx.doi.org/10.1080/14786441008563088

$$
\text { 曲 Published online: } 18 \text { May } 2009 .
$$

Submit your article to this journal

LII Article views: 2

Q View related articles $\asymp$ 
METEOROLOGICAL TABLE, By Mr. Carey, of the Strand,

For April 1810.

\begin{tabular}{|c|c|c|c|c|c|c|}
\hline \multirow[b]{2}{*}{$\begin{array}{l}\text { Days of } \\
\text { Month. }\end{array}$} & \multicolumn{3}{|c|}{ Thermometer. } & \multirow[b]{2}{*}{$\mid \begin{array}{c}\text { Height of } \\
\text { the Barom. } \\
\text { Inches. }\end{array}$} & \multirow[b]{2}{*}{ 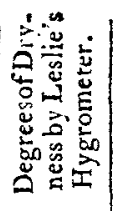 } & \multirow[b]{2}{*}{ Weather. } \\
\hline & 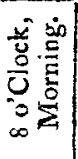 & 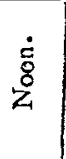 & $\begin{array}{l}x \\
0 \\
0 \\
0 \\
0 \\
0 \\
=\end{array}$ & & & \\
\hline March 27 & 44 & $52^{\circ}$ & $42^{\circ}$ & $29 \cdot 59$ & 0 & Rain \\
\hline 28 & 44 & 50 & 40 & $\cdot 78$ & 22 & Fair \\
\hline 29 & 40 & 51 & 39 & $\cdot 90$ & 20 & Showery \\
\hline 30 & 40 & 49 & 42 & $\cdot 85$ & 25 & Cloudy \\
\hline 31 & 43 & 51 & 45 & $\cdot 62$ & $\mathbf{0}$ & Showery \\
\hline April 1 & 45 & 49 & 42 & 40 & 0 & Showery \\
\hline 2 & 40 & 45 & 40 & $\cdot 72$ & 15 & Cloudy \\
\hline 3 & 43 & 56 & 46 & $\cdot 60$ & 21 & Cloudy \\
\hline 4 & 45 & 47 & 39 & $\cdot 30$ & 0 & Rain \\
\hline 5 & 37 & 47 & 45 & $\cdot 69$ & 36 & Fair \\
\hline 6 & 42 & 45 & 42 & $\cdot 22$ & $\mathbf{o}$ & Stormy \\
\hline 7 & 41 & 53 & 43 & $\cdot 30$ & 31 & Clourly \\
\hline 8 & 44 & 51 & 43 & $\cdot 58$ & 20 & Cloudy \\
\hline 9 & 45 & 48 & 44 & $\cdot 45$ & $\mathbf{0}$ & Rain \\
\hline 10 & 44 & 42 & 39 & $\cdot 55$ & $\mathbf{0}$ & Rain \\
\hline 11 & 37 & 42 & 36 & $\cdot 65$ & 5 & Showery \\
\hline 12 & 33 & 41 & 34 & $\cdot 90$ & 25 & Cloudy \\
\hline 13 & 34 & 42 & 35 & $\cdot 89$ & 20 & Cloudy \\
\hline 14 & 36 & 47 & 39 & $\cdot 81$ & 26 & Cloudy \\
\hline 15 & 44 & 49 & 40 & .71 & 36 & Fair \\
\hline 16 & 39 & 47 & 40 & 48 & 10 & Showery \\
\hline 17 & 42 & 52 & 45 & $\cdot 64$ & 20 & Showery \\
\hline 18 & 48 & 36 & 46 & 70 & 35 & Cloudy \\
\hline 19 & 49 & 57 & 47 & $\cdot 80$ & 42 & Fair \\
\hline 20 & 48 & 57 & 45 & $30 \cdot 10$ & 39 & Fair \\
\hline 21 & 49 & 59 & 47 & $\cdot 17$ & 46 & Fair \\
\hline 22 & 50 & 63 & 54 & $\cdot 16$ & 40 & Fair \\
\hline 23 & 54 & 66 & 55 & -20 & 39 & Fair \\
\hline 24 & 54 & 63 & 44 & $\cdot 15$ & 40 & Fair \\
\hline 25 & 44 & 58 & 43 & $\cdot 14$ & 57 & Fair \\
\hline 26 & 47 & 59 & 45 & $\cdot 12$ & 65 & Fair \\
\hline
\end{tabular}

N,B. The Barometer's height is taken at one o'clock. 